\title{
A Study on the Market Needs and MTI Course Design
}

\author{
Zhang Biyun \\ School of Foreign Languages \\ Yan'an University \\ Yan'an, China \\ 26282663@qq.com
}

\begin{abstract}
This research, in the light of the current situation of translation education and its research in China, attempts to conduct a study on the market needs and MTI course design. To provide an objective insight into requirements of translation companies for prospective translators, a survey of translation companies has been conducted. The results show that the existing MTI course design could not completely meet the demand of translation market. Problems such as insufficiency of language enhancement courses, over-emphasis of translation theories, and shortage of practice-oriented and computer-aided courses come out to be the most serious ones. Therefore, based on the studies of some scholars in China on the translators' knowledge structure, the present research proposes a framework to the innovation of the present MTI course design, which includes four aspects, namely preparatory courses, practice-oriented translation courses, specialized translation courses, and computer-aided translation courses.
\end{abstract}

\section{Keywords-Market Needs; MTI; Course design}

\section{INTRODUCTION}

The 1990s saw the development of translation teaching from one or two courses in Foreign Language Departments into an independent department. In 1997, the first Translation Department was established in Guangdong University of Foreign Studies, which intended to educate professional translators for foreign trade, economy and commerce as well as international communication.

From the outset of 21 st century, with the constant endeavor of an array of translators and administrators, translation teaching in China has undergone immense reform and development. In 2006, the Ministry of Education granted three universities BTI (Bachelor of Translation and Interpreting). They are Fudan University, Hebei Normal University and Guangdong University of Foreign Studies. This great event symbolizes that translation has become an independent discipline and a complete system of translation education has shaped in China.

In 2007, to serve the international communication and social development, the State Academic Degree Committee of the State Council examined and conferred 15 universities MTI degree (Master of Translation and Interpreting), intending to educate "professional and practical translators and interpreters of high level" (A Guide to MTI Education, 2007, hereafter "the

This research is supported by Social Science Fund Project of Yan'an University "Research on the Dubbing Translation of Movies and Cultural Communication" (YDK2015-34)
Guide" for short).

The reform and achievements in translation education will definitely bring challenges to foreign language teaching and traditional translation teaching. MTI is a Professional Degree Program which is born to meet the requirement of the social development. Just as "the Guide" said, "As a professional degree program, MTI differs from other translation-oriented programs in many aspects, such as training objectives, teachers quality, pedagogy etc. [1]"

In recent years, with the development of politics, economy, culture, science and technology in China, professional translators are in great demand. Traditional translation teaching could not meet the requirements of the new circumstances any more. The development of high technology and informationization would definitely bring about challenges to translation teaching, especially MTI.

In order to survive in the fierce competition, universities with MTI have to redesign its courses. In 2017, MTI was granted by the Ministry of Education in Yan'an University. In light of this context, this research strives to conduct a study on the market needs and MTI course design, in the hope of providing enlightenment to the innovation of MTI course design, so as to meet the translation market needs.

\section{REQUIREMENTS OF TRANSLATION COMPANIES FOR PROSPECTIVE TRANSLATORS}

Market need is a crucial point that must be considered in MTI course design. The significance of market needs assessment could be seen from the comments of the following scholars. "One of the most important reasons of the success of western higher education is adequate reorganization on functions of market. In other words, market plays a decisive role in development direction, teaching goal and teaching scale in western higher education. [2]" "Professional translator training, at least, has to embrace three aspects: language skills and knowledge, encyclopedic knowledge (especially international policy, economy, law etc.) and translation techniques training (including professional knowledge of translation). [3]" Zhong Weihe believed in the same year that knowledge structure of translators should include three parts "language knowledge, encyclopedic knowledge and translation skills. [4]" Liu Heping is greatly in favor of their point of view, 
adding that "translation teaching, no matter what stage it is at, ought to include the three blocks of knowledge. [5]"

As a result, to provide an objective insight into requirements of translation companies for prospective translators, a survey of translation companies has been conducted. Requirements for translators of sixteen translation companies of various sizes ranging from Beijing, Shanghai, Hangzhou and Shenzhen to Xi'an have been collected online and studied to investigate the needs of the society.

Although translation industry in China has not got on the right track, it has already developed into a large scale with thousands of translation companies and millions of translators of all kinds and all walks, and the requirements of translation companies for prospective translators have become much clear and widely acceptable. Several basic and agreeable requirements have been concluded after studying their requirements.

First, most companies require employees to have Bachelor's Degree in English with the certificate of TEM (Test for English Majors) 8 or BTI or MTI with the certificate of CATTI (China Accreditation Test for Translators and Interpreters). Some companies clearly claim that applicants should be competent in both English and Chinese. Of course, bilingual competence is the most basic competence for translators.

Second, what is most common and challenging to applicants is that almost all the companies require applicants to acquire some specialized knowledge, such as law, IT, commerce etc. However, the awkward situation in China translation market is that postgraduates majoring in language lack encyclopedic knowledge, while those majoring in other sectors are incompetent in English. The question is without knowledge of specialized sectors, how can they become professional and advanced translators? Of course, it is not practical for MTI courses to equip them with good understanding in science or other specialized sectors. Nevertheless, MTI course design has responsibility in introducing them into certain specialized translation.

Large numbers of MTI graduates are working or will work as professional translators. This trend is also decided by the development of the society. Just as Meng Qingsheng remarked, "Rapid development of society and economy requires more practice-oriented translators. This requirement not only provides translation studies with theoretical foundation, but also provides translator training with authentic basis. [6]"

Third, another challenge to applicants is mastering translation software. Information technology has already been frequently applied in translation industry. Translation software could considerably accelerate translation speed and efficiency. Therefore, prospective translators must be acquainted with translation software, such as TRADOS. Although it may not be difficult to students and they will master it during work, translation companies wish that their employees could use it without any delay of work.

Fourth, most translation companies, especially larger companies tend to employ applicants with a work experience of at least 5 years, so postgraduates should do as much translation practice as possible in their spare time to be rich in translation experience. Therefore, MTI course design should supply enough practical translation curricula, and teachers should try their best to provide practical opportunities and activities in their teaching process.

In consideration of the requirements of translation companies for prospective translators, the present study will probe into the problems in the existing MTI courses, and propose a framework to the innovation of the MTI course design, so as to pave the way for the curriculum design in Yan’an University.

\section{PROBLEMS IN THE EXISTING MTI COURSE DESIGN}

Dai Weidong pointed out that the cultivation of English talents needs to enhance the relationship of teaching and social demand [7]. That is, English education must be done in accordance with the social requirement so as to educate graduates with multiple qualifications. Li Defeng also suggested that in the process of translation course design, the relationship among the needs of education, learners and the translation market ought to be considered. "Ignorance of the changes and improvement of learners' and social needs in curriculum design would definitely lead to a waste of time and money. Without doubt, this kind of curriculum surely could not educate qualified translators for society. [8]"

However, MTI curricula in most universities in China have never been updated in the past three decades. The investigation done from the perspectives of translation market requirement makes it clear that these curricula are rather problematic. MTI graduates cannot find satisfying jobs because they are unable to meet the requirement of translation market; and for those who are at work, they feel incompetent to finish their work. MTI course design comes out to be so independent of translation market.

To be exact, the existing MTI curricula in most universities have violated students' cognitive law by offering courses at random and at will. In teaching content, there is a shortage of language enhancement courses, translation-related courses, especially specialized translation courses. In addition, in the modern information-based society, there are barely computer-aided translation courses of MTI curricula in China.

This study has chosen seven universities with MTI admission qualification in China as a case study, which are Beijing Foreign Languages Studies University, Nankai University, Nanjing University, Nanjing Normal University, Tianjin University, Shanghai International Studies University and Sichuan International Studies University. Among all the required courses for MTI students in these universities, practical translation courses remain an indispensable part, yet the content of these courses is inappropriate for there is too much literary translation but little practical or specialized translation and most teaching materials are outdated, which are far from meeting social demand. Consequently, more authentic teaching materials should be brought into MTI course design. Moreover, translation of specialized sectors or styles covered in these courses is too general to be mastered by students for limited teaching hours. 
The study of curricula in the seven universities in China indicates that in the whole, almost none of these universities could completely meet the demands of translation market.

Therefore, there is cry for improvement for MTI students in translation and interpreting competence through taking courses, which requires the MTI course design to offer enough practice-oriented translation courses. The urgent demand for more and effective computer-aided courses is also appealing.

In brief, problems in the excising MTI course design cover insufficiency of language enhancement courses, over-emphasis of translation theories, as well as shortage of practice-oriented and computer-aided courses.

\section{A FRAMEWORK TO THE INNOVATION OF THE MTI COURSE DESIGN}

Based on what has been discussed in the previous parts, the present research will propose a framework to the innovation of the present MTI course design, which can be illustrated in the following four aspects:

\section{A. Preparatory Courses}

Preparatory courses here refer to language enhancement courses and some translation-related knowledge courses, which could prepare students to study advanced or more difficult translation courses. Most preparatory courses offered currently are of literature and linguistics, with few for specialized translation. To improve the present MTI course design, special emphasizes should be laid on students' bilingual competence. Before admission, students should be asked to achieve high marks in both Chinese and English. Then, language enhancement courses ought to be offered as compulsory courses for MTI students.

Some optional preparatory courses are: Modern Chinese and English Linguistics, Chinese and Western Mode of Thought, Contrastive Languages, Communication, Language competence, Cultural Issues for Translators, Literature and so on to prepare MTI students before doing translation and interpretation. Varied and plentiful courses ranging from culture to modern technology and professional quality of translators and interpreters can be offered to cater to the needs and interests of MTI students.

\section{B. Practice-oriented Translation Courses}

Exactly speaking, E-C and C-E Translation courses are not practice-oriented since these courses tend to introduce basic knowledge and techniques of translation with little practice. However, in all the 24 colleges mentioned in Part III, the most common so-called practice-oriented courses are E-C and C-E Translation or interpretation.

Some advanced translation practice courses are in urgent need, such as Translation Theory and Practice, Literature and Tourism Translation and Science, Technology, Economy and Trade Translation.

In addition, practice-oriented translation courses such as General Translation, Subtitling and Dubbing, Consecutive and Simultaneous Translation can be offered to MTI students.

\section{Specialized Translation Courses}

Specialized translation is what the translation market needs most, so specialized translation courses should be highlighted in MTI courses design, for they are designed to cultivate professional translators in certain fields.

The specialized courses that should be offered cover the major social sectors, such as Politics, Economics, Science, Technology, Commerce, Law, Literary, Media as well as translation practicum for MTI students. Besides, universities with MTI should hold their characteristics in line with their own teaching goals. Taking Yan'an University for example, it can open some translation courses related to the Yan'an period and tourism of revolution due to its unique teaching purposeto cultivate excellent and professional translators and interpreters with the spirit of Yan'an.

\section{Computer-aided Translation Courses}

In the era of information and technology explosion, computer-aided courses must be supplied to MTI students in that they could greatly improve translation speed and quality. Some recommended computer-aided courses are Computer Literacy, Computing in Translation, Terminology and Computer as well as Machine Translation.

\section{E. Summary}

Course design is a quite complicated project, which requires taking market needs into consideration. Referring to the conclusion drawn from the surveys of this study, the following courses will be suggested to open for translation students.

First, language enhancement courses of both English and Chinese are a must for students of translation. Courses like Advanced English, Chinese Writing or Selected Readings on Chinese and English Literature could be offered. Translation is a comprehensive discipline, and students of English, as the results show previously, are usually short of encyclopedic knowledge, so preparatory courses like Linguistics, Business, commerce etc. should be introduced. Preparatory courses should coincide with the specialized courses.

Of course, specialized translation courses should be offered as well for they could greatly improve students' translation competence. Courses such as Translation of Legal \& Political Texts, Translation of Economic \& Commercial Texts, Consecutive Interpretation of Scientific and Technical Texts etc. could be included in MTI curriculum.

Other practice-oriented courses like general translation and interpreting should also be an indispensable part in MTI curriculum. Computer-aided courses must be supplied to students which could greatly accelerate translation speed and efficiency. Apart from practice-oriented courses, theoretical courses on translation are also important for MTI students.

Not all universities could offer all of the courses mentioned above, but every MTI curriculum should have a complete framework embracing preparatory courses, general practice-oriented translation courses, specialized translation courses, computer-aided translation courses and theoretical courses. Besides, universities could offer some characteristic translation courses to differ from other universities. 


\section{CONCLUSION}

The present study aims at exploring problems of the existing MTI course design in China and providing a framework to the innovation of the curriculum.

The present study has detected lots of problems in MTI course design in China. Since the existing MTI curricula in most universities in Mainland China have never been updated with social development, they could not meet the requirements of translation market.

First, language enhancement courses are urgently needed. Second, practice-oriented, especially specialized translation courses display great blanks in MTI curriculum in the Mainland China.

Therefore, the present study suggests reconstructing the existing curriculum by providing a framework, which includes four major proportions-preparatory courses including language enhancement courses and encyclopedic knowledge enhancement courses; practice-oriented translation courses including general translation courses and specialized translation courses; theoretical courses on translation and computer-aided translation courses. Meanwhile, the study suggests that different universities could offer their own characteristic courses based on their own status quo and strengths.

In addition, in MTI course design, universities should strive to strike a better balance between three pairs of contradictions, which are theoretical courses and practice-oriented courses; translation training and language training as well as translation competence improvement and translation market.

\section{ACKNOWLEDGMENT}

This research is supported by Social Science Fund Project of Yan'an University "Research on the Dubbing Translation of Movies and Cultural Communication" (YDK2015-34).

I am greatly indebted to the sixteen translation companies for taking their precious time to help me investigate the requirements of the translation market. They are Beijing Yuanpei Translation Co., Ltd, Beijing 3Trans Translation Co., Ltd, Transn Co., Ltd, GTC Technology Co. Ltd, Nanjing BBT Trans Co. Ltd, Xinhua Translation Agency, Shanghai Xiaotong Translation Co., Shanghai Boyu Translation Co., Ltd, Shanghai Yulin Translation Co., Ltd, GBT Translation Co., Shenzhen Yayan Translation Co., Shanghai Xialian Translation Co., Ltd, Xi'an Jinke Translation Co., Ltd, Hangzhou Glossa Translation Co., Ltd, Beijing Solid Works Translation Co., Ltd, and Shanghai Zhuoao Culture Communication Co ., Ltd .

Thanks also go to the seven universities with MTI admission qualification in China, namely, Beijing Foreign Languages Studies University, Nankai University, Nanjing University, Nanjing Normal University, Tianjin University, Shanghai International Studies University and Sichuan International Studies University.

\section{REFERENCES}

[1] Academic Degrees Committee of the State Council . Notice on "Scheme of Degree Design for MTI," Degree [2007], No. 11.

[2] Wang Xiaobing, "Development of Cluster Modular Course Based on Market Demand," Journal of Human University of Science \& Technology (Social Science Edition), vol. 13, pp. 109-110, June, 2008.

[3] He Qixin, “Translation and Foreign Language Teaching," Chinese Translators Journal, pp.11-12, July, 2007.

[4] Zhong Weihe, "Interpreting Course Setting and Innterpreting Teaching Principle," Chinese Translators Journal, vol. 24, pp. 52-53, January, 2007.

[5] Liu Heping, "On the Constgruction of Translation Teaching System," Chinese Translators Journal, pp. 35-39, May, 2008.

[6] Meng Qingsheng, "Translation Major Setting Oriented to Market Demand," Science \& Technology Information, p. 176, November, 2007.

[7] Dai Weidong, "Building a 'One-stop' English Teaching system with Chinese Characteristcs," Foreign Language Teaching and Research, pp. 322-327, September, 2001.

[8] $\mathrm{Li}$ Defeng and $\mathrm{Hu} \mathrm{Mu}$, "Curriculum Developmeng In Trranslation Education: A Learner-Centered Approach," Journal of Foreign Languages, pp. 59-65, March, 2006. 